\title{
THE DIGITAL ADVERTISING ECOSYSTEM VISUALIZATION - LITERATURE REVIEW
}

\author{
Valerio Stallone and Michael Klaas ${ }^{1}$ \\ ${ }^{1} \mathrm{Dr}$ \\ Zurich University of Applied Sciences, Center for Digital Marketing \\ Stadthausstrasse 14, CH-8400 Winterthur, Switzerland
}

\begin{abstract}
In this reflection paper, we suggest the need for a standardization of digital advertising ecosystem conceptual flow visualizations. We do so, because of the diversity of available visualizations of both concepts in literature and the accompanied risk of wrong conclusions. We therefore recommend a visualization in the field of digital advertising, which should be challenged in future research.
\end{abstract}

\section{KEYWORDS}

Digital Marketing, Display Advertising, Programmatic Advertising, Real-Time Bidding, Digital Advertising Ecosystem

\section{INTRODUCTION}

The digital marketing technology landscape is pacing at a high speed and is changing as we speak. In this reflection paper, we focus on the technology applications that build an ecosystem, which enables publishers to connect to advertisers. In the ecosystem that has evolved in literature we find a setting of intermediaries who are taking part in an auction, which connects buyers and sellers of a unique, indivisible good: The impression (Feldman et al., 2010). Researchers have tried to keep up with the pace by modelling and analyzing different aspects of marketing technology adaptations. In this reflection paper we have analyzed literature, which discussed at least two elements of the digital advertising ecosystem ("DAE") and dated 2015 or younger. By doing so, we are able to recommend a visualization of the DAE, which future researchers should rely upon for their studies. This review starts with an introduction to the historical background and moves forward to the methodologies scholars have worked with when using the DAE in literature. In the last chapter, we suggest a standardization of the DAE visualization for scientific literature as well as for work in non-academic fields.

\section{HISTORICAL BACKGROUND}

First researches on the marketplace started visualizing it in the end of the past decade (Muthukrishnan, 2009): The focus was on "the way of selling and buying ads on the Internet via an exchange (market) hat brings sellers (supply) and buyers (demand) together". The supplier not only supplies the advertising inventory, but also human eyes, which should generate the interaction that is the main resource elements on all sides of the platform depend upon: Attention (Muthukrishnan, 2009). This transaction has grown in the last decade to an extent with an increasing amount of companies trying to be a part of it (Sayedi et al., 2017). The marketplace evolved into an ecosystem, the DAE. It outgrew the simple exchange platform and added new elements to it: While keeping the supply, the demand, the market and the user side, the DAE has been completed in practice by the data side (Callejo, 2015; Yuan, 2015; Gardh and Amnäs, 2017; Papadopoulos et al., 2017; Wang, Zhang and Yuan, 2017; Iordanou et al., 2018). So-called data management platforms have emerged to help advertisers merge and manage data in large volumes in order to make better buying decisions (Nicholls, Malins and Horner, 2013). 


\section{METHODOLOGIES}

As stated in the previous chapter, the DAE can be divided into five segments: demand side, supply side, market, data and the user (Wang, Zhang and Yuan, 2017). The demand side contains the players who are spending advertising money, whereas those actors, who are actually responsible for the advertising inventory, represent the supply side. In the market, demand and supply meet to exchange the slot for money based on a second price auction (Zhang, 2018). The user interacts with the supply side, since it is the author of the main resource players on all sides of the ecosystem are depending on. Both, supply and demand side as well as third party actors, who enrich the information flow to make the user more transparent, create the data layer. The analysis of the literature - journals, book chapters, conference proceedings \& theses - controls for the presence of the five segments presented as well as the density of elements within those segments.

Visualizations of the digital advertising ecosystem vary from very simple versions with only two players (Alaimo and Kallinikos, 2018) to thirteen elements (Iordanou et al., 2018). They vary in sizes, shapes, colors, symbols used and in directions. Research report the time component differently: From the advertising request due to the HTML request of a user on supply side to the delivery of the ad, their opinions differ. Latter go from less than 100ms (Yuan, 2015; Chaudhuri, Bagherjeiran and Liu, 2017; Papadopoulos et al., 2017; Parssinen et al., 2018) to around 100ms (Chen et al., 2017; Niu et al., 2017; Iordanou et al., 2018), to longer than 100ms (Dwyer and Kanguri, 2016, 2017; Kumar, 2017).

Visualizations in literature differ in elements mentioned: Not every scholar saw the need to mention, at least graphically, all the players involved in the digital advertising ecosystem. Some of them even ignore entire categories we described in this chapter. It leads to ignoring the data part (15 out of 25), to not mentioning the user (6 out of 25). Four out of twenty-five pieces do not contain neither the data, nor the user segment. Out of the eight pieces published in 2018, four were complete containing all groups (2017: 3 out of 10; 2016: 0 out of 4; 2015: 1 out of 3). One thesis (out of 5), both book chapters, three conference proceedings (out of 7) and only two journal articles (out of 11) contained all segments.

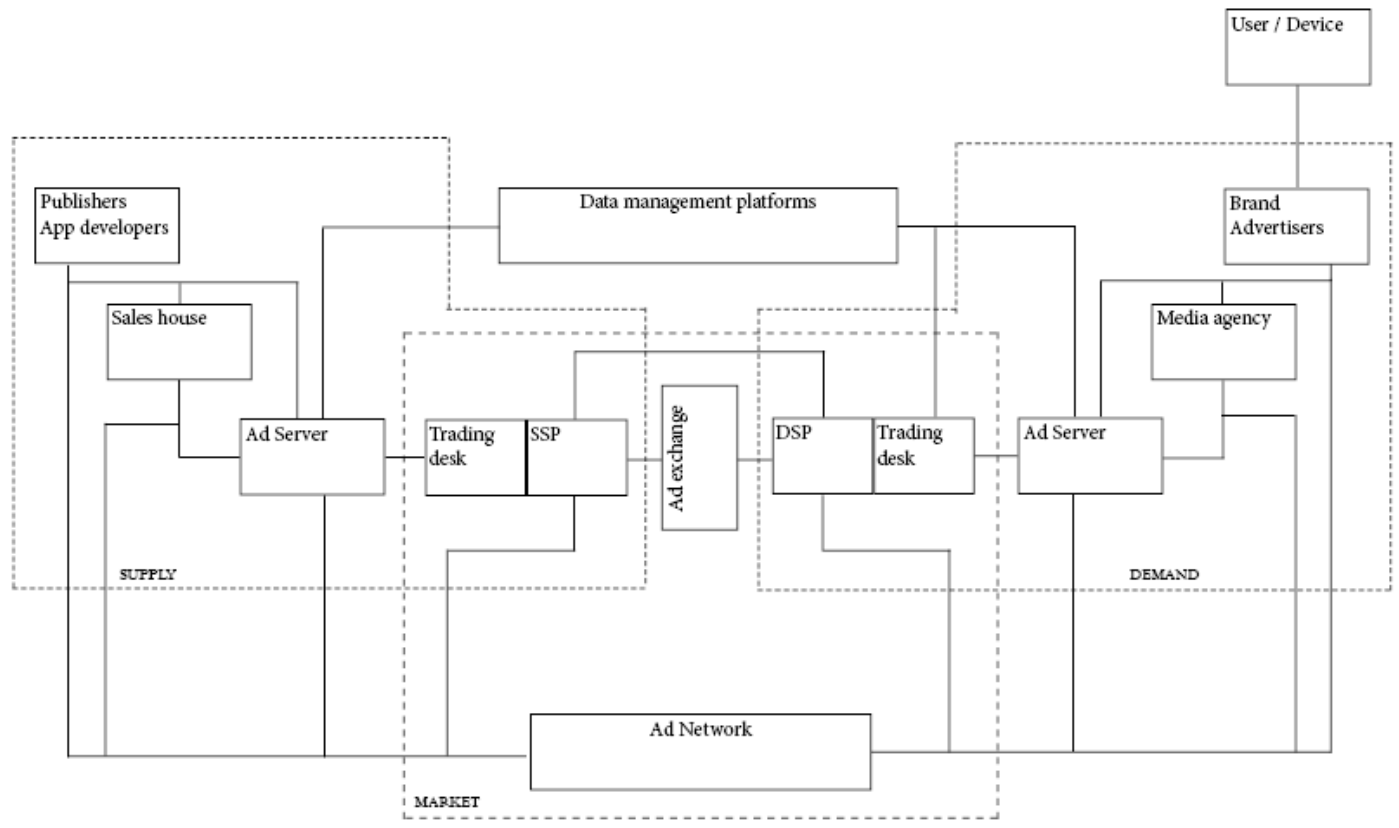

Figure 1. The DAE displayed below contains a minimum viable amount of players based on the literature reviewed. It represents the DAE as complete but as minimalized as possible 


\section{CONCLUSION}

We conducted a review of DAE visualizations in literature to find a wide assortment of different version. In our analysis, we focused on digital advertising literature mentioning at least two key players or elements. We saw a slight positive development going from 0 to $50 \%$ completeness in the DAE visualization from 2015 to 2018. In Figure 1 we created a DAE visualization, which shows all the segments and the elements within them. We based this "minimum viable version" on the literature review.

In the opinion of the authors, future research should focus on the following questions: Does the industry accept our DAE in Figure 1? If no, which elements are gone missing? For future research, we therefore suggest carrying an in-depth description and qualitative analysis of the various ecosystems displayed in scientific and non-scientific visualizations based on this paper and move the discussion to the public eye. As mentioned in a recent paper, "there needs to be a significant awareness campaign to support transformation toward a healthier online advertising ecosystem" (Parssinen et al., 2018).

\section{REFERENCES}

Aksu, H. et al. (2018) 'Advertising in the IoT Era: Vision and Challenges', IEEE Communications Magazine, pp. 1-7. doi: 10.1109/MCOM.2017.1700871.

Alaimo, C. and Kallinikos, J. (2018) Objects, Metrics and Practices: An Inquiry into Programmatic Advertising, IFIP Advances in Information and Communi- cation Technology. San Francisco. Available at: https://www.researchgate.net/publication/327919972 (Accessed: 20 October 2018).

Arab, S. A. et al. (2018) 'Two-Layer Recommendation-Based Real Time Bidding (RTB)', in 2018 IEEE 27th International Conference on Enabling Technologies: Infrastructure for Collaborative Enterprises (WETICE). IEEE, pp. 91-94. doi: 10.1109/WETICE.2018.00024.

Callejo, P. (2015) Master on Telematics Engineering Auditing Methodology to Asses the Quality of Online Display Advertising Campaigns. Available at: http://eprints.networks.imdea.org/1483/1/TFM_Patricia_Callejo.pdf (Accessed: 20 October 2018).

Chaudhuri, S., Bagherjeiran, A. and Liu, J. (2017) 'Ranking and Calibrating Click-Attributed Purchases in Performance Display Advertising', in Proceedings of the ADKDD'17. doi: 10.1145/3124749.3124755.

Chen, G. et al. (2016) 'In-Depth Survey of Digital Advertising Technologies', IEEE Communications Surveys \& Tutorials, 18(3), pp. 2124-2148. doi: 10.1109/COMST.2016.2519912.

Chen, Y. et al. (2017) 'Measuring Network Reputation in the Ad-Bidding Process', in Detection of Intrusions and Malware, and Vulnerability Assessment. Springer, Cham, pp. 388-409. doi: 10.1007/978-3-319-60876-1_18.

Dwyer, C. and Kanguri, A. (2016) 'Gone in 200 Milliseconds: The Challenge of Blocking Malvertising', Student and Faculty Research Days, Available (3). http://digitalcommons.pace.edu/sfresearchdayhttp://digitalcommons.pace.edu/sfresearchday/3 (Accessed: 20 October 2018).

Dwyer, C. and Kanguri, A. (2017) 'Malvertising - A Rising Threat To The Online Ecosystem', Journal of Information Systems Applied Research. Association of Information Technology Professionals, Education Special Interest Group, 10(3), pp. 29-37. Available at: http://jisar.org/2017-10/n3/JISARv10n3p29.html (Accessed: 20 October 2018).

Feldman, J. et al. (2010) 'Auctions with Intermediaries', in EC '10 Proceedings of the 11th ACM conference on Electronic commerce, pp. 23-32. doi: https://doi.org/10.1145/1807342.1807346.

Gardh, M. and Amnäs, U. (2017) Trading with digital ads. KTH. Available at: https://pdfs.semanticscholar.org/53de/e01d71afffc5b7f0290da2c6e0c5502d6dc5.pdf (Accessed: 20 October 2018).

Gupta, S. and Mishra, A. (2018) 'Real Time Bidding With Comparative Study of Various User Responses Prediction Models', in International Conference on Recent Innovations in Management, Engineering, Science and Technology. Bareilly, p. 10. Available at: http://data.conferenceworld.in/IEEERAJSHREE/P493-502.pdf (Accessed: 29 October 2018).

Haider, C. M. R. et al. (2018) 'An ensemble learning based approach for impression fraud detection in mobile advertising', Journal of Network and Computer Applications, 112, pp. 126-141. doi: 10.1016/j.jnca.2018.02.021.

Högström, J. and Wallin, E. (2017) Programmatic Advertising: A Quantitative Study of Consumer Attitudes Towards Highly Frequent Online Ads. Halmstad University. Available at: http://www.divaportal.org/smash/get/diva2:1106048/FULLTEXT01.pdf (Accessed: 29 October 2018). 
Iordanou, C. et al. (2018) 'Tracing Cross Border Web Tracking', in Internet Measurement Conference (IMC '18), October 31-November 2, 2018, Boston, MA, USA. Boston: ACM, p. 14. doi: 10.1145/3278532.3278561.

Kumar, J. (2017) 'Timeout Analysis, Troubleshooting and Notification in Real Time Bidding Advertising System with Implementation', Computer Science and Engineering, 7(3), pp. 67-78. doi: 10.5923/j.computer.20170703.01.

Muthukrishnan, S. (2009) ‘Ad Exchanges: Research Issues’, in. Springer, Berlin, Heidelberg, pp. 1-12. doi: 10.1007/9783-642-10841-9_1.

Nicholls, S., Malins, A. and Horner, M. (2013) Real-Time Bidding in Online Advertising - The Death of the Mad Men. Available at: http://printarchiv.absatzwirtschaft.de/pdf/Studie_Real_Time_Bidding_in_Online_Advertising.pdf (Accessed: 20 October 2018).

Niu, C. et al. (2017) 'ERA: Towards privacy preservation and verifiability for online ad exchanges', Journal of Network and Computer Applications, 98, pp. 1-10. doi: 10.1016/j.jnca.2017.08.012.

Papadopoulos, P. et al. (2017) 'If you are not paying for it, you are the product: How much do advertisers pay to reach you?', in Proceedings of IMC '17, London, United Kingdom, November 1-3, 2017. London, p. 15. doi: $10.1145 / 3131365.3131397$

Parssinen, M. et al. (2018) 'Is Blockchain Ready to Revolutionize Online Advertising?', IEEE Access, pp. 1-1. doi: 10.1109/ACCESS.2018.2872694.

Sayedi, A. et al. (2017) Real-Time Bidding in Online Display Advertising. Available at: https://papers.ssrn.com/sol3/papers.cfm?abstract_id=2916875 (Accessed: 29 October 2018).

Trofimov, B. F., Arsiriy, E. A. and Arsiriy, A. V. (2015) 'User identification problems on DSP side in terms of advertising RTB auctions', in 2015 Information Technologies in Innovation Business Conference (ITIB). IEEE, pp. 97-100. doi: 10.1109/ITIB.2015.7355063.

Wang, J., Zhang, W. and Yuan, S. (2017) Display Advertising with Real-Time Bidding (RTB) and Behavioural Targeting. Boston: now publishers inc. Available at: https://arxiv.org/pdf/1610.03013.pdf (Accessed: 29 October 2018).

Yamaguchi, Y. et al. (2016) 'Web Advertising Recommender System Based On Estimating Users' Latent Interests', in Proceedings of the 18th International Conference on Information Integration and Web-based Applications and Services. Singapore, pp. 42-49. doi: 10.1145/3011141.3011180.

Yuan, S. (2015) Supply Side Optimisation in Online Display Advertising. University College London. Available at: http://discovery.ucl.ac.uk/1463229/1/ShuaiYuan-PhD-thesis.pdf (Accessed: 20 October 2018).

Zhang, Y. (2018) Mathematical Approaches to Real Time Bidding Strategy (RTB) for Advertising Campaigns for Demand Side Platforms $(D S P)$. NYU Available anghai. https://cdn.shanghai.nyu.edu/sites/default/files/zhang_yiyi_thesis_nyush_honors_2018.pdf (Accessed: 20 October 2018).

Zhou, B. and Shariat, S. (2016) 'Finding Needle in a Million Metrics: Anomaly Detection in a Large-scale Computational Advertising Platform', in Proceeding of the 2nd International Workshop on Ad Targeting at Scale. San Francisco. Available at: https://arxiv.org/pdf/1602.07057.pdf (Accessed: 20 October 2018).

Zhu, X. et al. (2017) 'Ad Ecosystems and Key Components', in Fraud Prevention in Online Digital Advertising. Springer, Cham, pp. 7-18. doi: 10.1007/978-3-319-56793-8_2. 